\title{
Obstacles and Challenges in Management of Social Cooperation in Administration of Zone 3, Isfahan, Iran
}

\author{
Mohammad Ali Firoozi ${ }^{1}$, Majid Goodarzi ${ }^{2} \&$ Abdolmotalleb Akbari ${ }^{3}$ \\ ${ }^{1}$ Associate Professor of Geography and Urban Planning, Shahid Chamran University, Ahwaz, Iran \\ ${ }^{2} \mathrm{Ph} . \mathrm{D}$ Student of Geography and Urban Planning, University of Isfahan, Isfahan, Iran \\ ${ }^{3}$ Department of Geography and urban planning, Payame noor university, i.r.of iran \\ Correspondence: Mohammad Ali Firoozi, Geography and Urban Planning, Shahid Chamran University, Ahwaz, \\ Iran. Tel: 98-916-313-2677. E-mail: M.alifiroozi@scu.ac.ir
}

Received: July 16, 2012 Accepted: August 8, 2012 Online Published: August 31, 2012

doi:10.5539/jgg.v4n4p12 URL: http://dx.doi.org/10.5539/jgg.v4n4p12

\begin{abstract}
The present research aims to recognizing the effective factors on reduction of social cooperation with the purpose of attracting social cooperation in directing city zones (zone 3, Isfahan, Iran). The methodology is based on documental and survey methods. The statistical sample of this research contains over 18 year-old people who live in zone number 3 inIsfahan, from whom 385 individuals were chosen as the sampleofthis research using Cochran method. To collect data, a researcher made questionnaire (analysis of effective factors on social cooperation in directing city zones) was utilized. The findings show that the effectiveness rate of cooperation, trust on executives and organizations, training, residency status, education status, stimulus, and the role of the person in the family are preventing factors of social cooperation in directing the city zones (zone number 3 inIsfahan). Therefore, if the responsible authorities are fond of removing the obstacles of social cooperation in directing the city zones (zone number 3 in Isfahan), they should think of the above mentioned obstacles and decide on these items for their long term goals.
\end{abstract}

Keywords: social cooperation, citizens, management, social standpoint, city zones

\section{Introduction}

\subsection{The Issue Plan}

The widespread belief about inefficiency of canonized planning among experts and scholars has been confirmed by various urban plans and different studies. Different kinds of information are utilized in urban planning procedures by experts. Data about stockholders and different organizations are gathered and managed in order to protect decision making and designing physical environment. Perceptional quality and inhabitants' use of living environment are needed (Kytta \& Kahila, 2006, p. 137). Therefore, cooperative, bottom-up planning has been substituted for top-down ones. Decentralization and localization are, indeed, assigning similar units (individual themselves) to do the local affaires which leads to establishing a local unit in urban management system. Thus, the contemporary literature on international planning emphasizes on how to take use of local planning procedures through direct engagement of interested people and/or those possibly affected by planning consequences (Healey, 1998, p. 132). Nowadays, cooperation is considered as a major and inseparable developmental factor which gains importance and significance so that the UNHDR (1993) states that "People cooperation is gradually becoming the main issue of our time" (Atal, 1999, p. 27). Hence, the modern developmental approach emphasizing people's role in development procedure and following in-born developmental approaches, consider people as creative and active factors in development process. It is the reason why" the necessity of creative cooperation in social and political decision-making by large stratum of society" has been emphasized (Azimi, 1993, p. 52). Consequently, the new legal demands in most of the countries as well as the emphasis by planning professors, the environmental groups and local associations, has forced local units to look for methods in order to accept consultative processes (Brackertz et al., 2005, p. 66). Therefore, higher cooperation by citizens, as a new legal necessity, will lead to combining small powers. In this regard, citizen's engagement in strategic planning cycle is suggested by new legal demands whose aims are providing methods for public corporation in local issues management. Local units have confronted the usual problems: How to 
recognize that representatives can reflect the viewpoints of active social members and how the groups can cooperate in decision making process. Moreover, forcing citizens to discuss the substitute future city inevitably includes important logistic challenges and entails structural changes, development and training for staff. However, planning must seek for improving, not changing the laws and regulations. Contemporary programmers face with urban zones which contains previous context and consequences. Since we do not enjoy suitable terms in this field, we need more realistic beliefs in which the result and consequence is more important than the process. Therefore, modern current planning must not ignore and omit the individuals. Maybe the time has come to spend much more energy for the issues which include more than the two percent of the whole population (issues except modern urban centers and conventional zones) and direct our attention toward people's mental, social and economic health. Unlike what mentioned by some planning theories, citizenship in urban areas which is considered a real part in planning is not sick and ill (Hillier \& Gunder, 2005, p. 94).

\subsection{Study Area}

Isfahan province with about $105,937 \mathrm{Km}^{2}$ is located in the center of Iran. The historical-tourist city of Isfahan is the capital city of this province. This city enjoys the third place concerning population across the country. The distance from Isfahan to Tehran (Iran's capital) is $425 \mathrm{Km}$ and is located in its south. Isfahan which enjoys a suitable geographical location and is located in the heart of Plateau of Iran has attracted the attention of Sultans and administrators. Isfahan city has 14 urban zones.

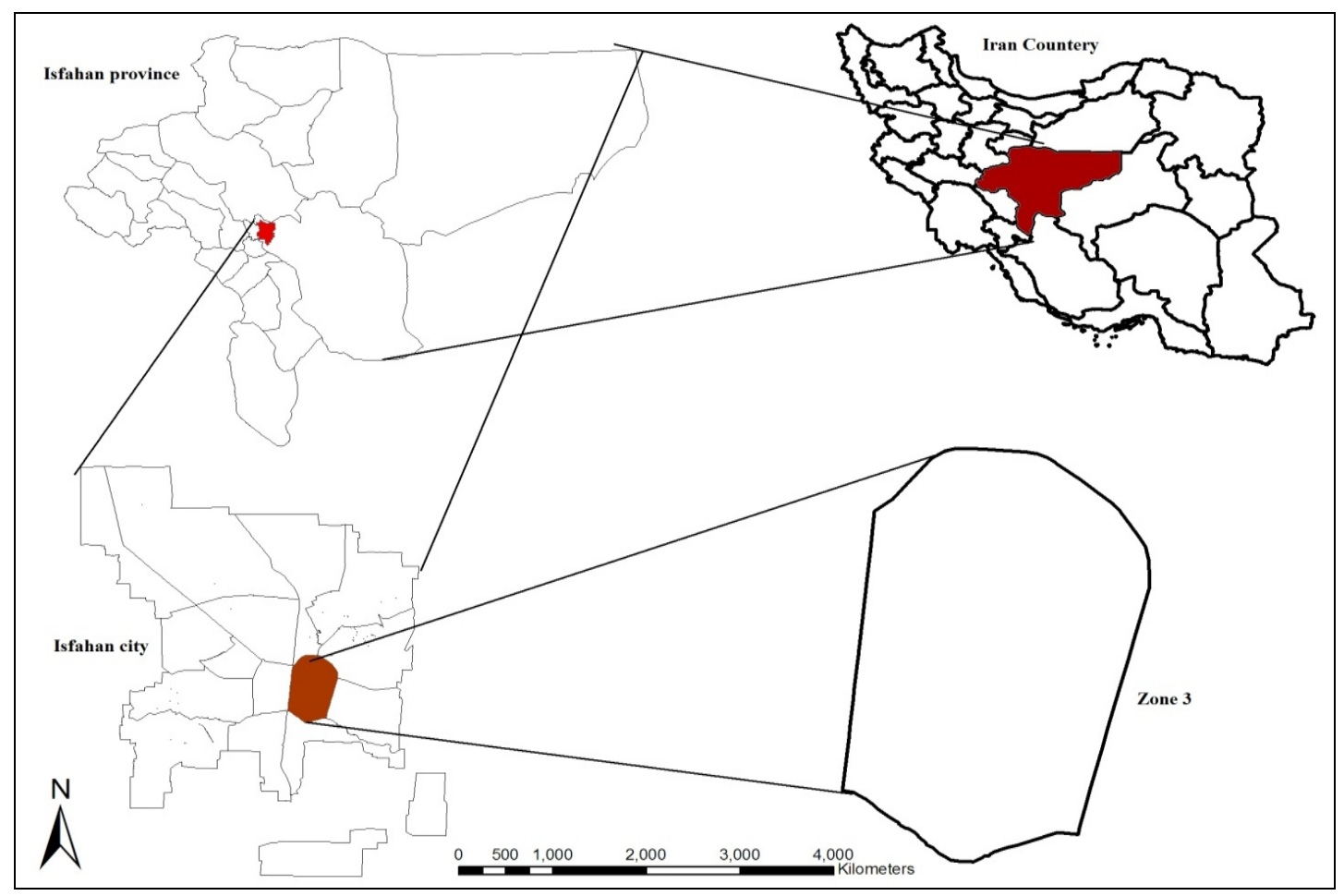

Figure 1. Spatial location map of Isfahan City in Isfahan province and Iran

Source: governor-general of Esfahan, 2012. Drawing: the researchers

\subsection{Significance of the Study}

Supporting the governmental models in response to political law convergence, in relation with trust and management application, is due to service improvement (Pieryre \& Poters, 2000, p. 17). The contemporary literature on planning shows that local units' processes and policies have been designed to improve social cooperation and support and have positive multiple feedbacks. For example, vast social cooperation in local units leads to supporting state policies (Ames, 1997), strengthening state's formality, (Amalric, 1998, p. 204) and distributing power within the society and compensating unfairness and social deprivation (Cat \& Murphy, 2003, p. 525). Therefore, the role of social cooperation is to gather information for programs to pass future sustainable laws. The cooperation process, as a functional system at macro-, average- and micro-levels accompanies 
functions such as social stability, accretion reinforcement, and group conflict decrease, removal of slummering culture, talents and innovation bloom, democratic values expansion, power resource sharing and responsibility reinforcement. Rahnama (1999) mentions four functions for cooperation: perceptual, social, political and instrumental, emphasizing the key role of cooperation in human oriented development. According to perceptual function, cooperation produces discourse and developmental operations which relies on different ways of realizing facts about development. In this regard, the perceptual system gains significance which can reflect the cultural heritage and local knowledge of the people themselves. From social point of view, cooperation has renovated the development discourse and can put units, groups and individuals engaged in development process in a new structural framework, and enable them to fulfill their major needs. From political point of view, cooperation can legitimize the development through enabling silent individuals in society. From instrumental point of view, cooperative approach calls upon the vulnerable to look for themselves, knowing the common traditional strategic defects of development and utilizing the enabling process. Goulet (1995) refers to people cooperation as the crucial part of the developmental strategies and considers three functions for it. From his viewpoint, social cooperation, firstly, ensures the non-instrumental government behavior with people and the vulnerability sprit through people. Secondly, cooperation is considered the most important solution in its own social situation. Furthermore, cooperation, acts as a channel through which groups and local societies can reach two major and larger decision making levels. From Goulet's point of view, "the developmental policies would be fruitless and unpopular without cooperation" (p.100).

\subsection{Social Cooperation}

So far several definitions and interpretations have been offered from cooperation. The vast notion of cooperation and its various interpretations is one of its specific characteristics. The background of this term refers to the beginning of human social life (Blacher, 2005, p. 153). Sir Geal (1976) mentions that "cooperation in decision-making is a charming notion in many countries but almost most individuals who take use of this expression think differently of it" (as cited in Lane, 2005, pp. 294-295). According to Hall, "the conflict between applicational viewpoints and most philosophical ones from cooperation has caused that the notion of cooperation changes to a multi-dimensional notion with different meanings in different times" (Azkiya \& Ghafari, 2000, p. 12). The expression of cooperation has been defined as "finding a share in sth and enjoying it and/or participating in a group and incorporating with it" by Allen Biro (Biro, 1990, p. 257). According to SalimeOmmar, cooperation process will result in people's interference and control what is considered a better life by themselves. The most fundamental thought about cooperation is accepting the equality maxim among people whose goal is to consult, cooperate in order to improve the quantity and quality of life in all social, economical and political fields. Cooperation is a process through which people can reach evolution and even create this evolution within themselves. Cooperation, in this sense, emphasize on human character and "is considered as a strategy which can create nice opportunities by which people can reach new ways of removing barriers and solving their difficulties" (Tusi, 1990, p. 5). The process of cooperation as an "enabling process" emphasizes on three basic values: a) sharing power with people, b) directing people toward surprising their own destiny, c) creating improvement opportunities for people. One of the most valuable aspects of cooperation is removal of slummering and blooming innovation and creativity in people. As Donald Michel states "people have more trust on themselves, do their best, and become innovative when they are allowed to cooperate in decision making process regarding their own lives. Here, they learn to act wisely against their life (as cited in Azimi, 1997, p. 47). To clarify the notion of cooperation, some definitions are presented here. French, a French sociologist, defines cooperation as "individual's mental and emotional engagement in a group situation which reinforces and stimulates the individual to help the group goals and share the group responsibilities and think of fulfilling the group goal (Ansari, 1995). Var (1975) has defined cooperation, from socio-psychological point of view, as engagement in an activity and social affectability (Azad, 1992, p. 63). From Almond and Pavel's point of view "cooperative activities are those through which normal citizen tries to affect the policy making" (Lmond $\&$ Pavel, 2000, p. 138). Some definitions of cooperation emphasize on the cooperation role in redistribution of economicand political power. From Abdolhay's point of view, cooperation is an instrument for expanding and distributing opportunities in order to cooperate in social decision making, assisting development and taking use of its consequences. From Alghanami point of view, cooperation is one of the most difficult and most controversial subjects in development which has been subject to value-based judgments. He defines the cooperation from political-social dimension as "optional participating in decision-making through organizations" (Alghanami, 1992, p. 60). Arneshain considers cooperation as redistribution of power "by which citizens who have been omitted from political and economical process are enabled to gradually participate in the future" (Okley \& Marsden, 1990, p. 33). As Yumalel states “cooperation generally means stimulating people's sensitivity and finally increasing their perception and ability to respond to developmental plans and also 
reinforcing local innovations (Patrick, 1994, p. 119). Gaotery considers cooperation as a public, continual, multiple, multi dimensional and multi-cultural process whose goal is attracting people to play a role in all developmental stages (as cited in Azkiya \& Ghafari, Op.cit: 13). Daram Guy, inspired Gren (1983) and Okley and Marsden (1984), distinguishes the three notions of cooperation. The first application indicates employing the people for taking the responsibility of social and economical development projects. Usually, these projects are thought and designed by top officials, while people are employed to carry them out. The second interpretation considers cooperation equal to decentralization in governmental organizations or respected systems. The third opinion thinks of cooperation as an allowance process to deprived and poor people. The notion of cooperation in his final viewpoint entails constructing democratic, independent organization, and poor's self reliance (Guy, 1991, p. 62). Some of the scholars has emphasized on basic characteristics of this notion in defining and determining the conceptual environment of cooperation. As MoorisXlard stated the expression of optional cooperation is used for certain groups (as it is distinguished from state communities), entering them as based on individual's selection (as it is distinguished from form like families) and also limited to group non-profit cooperation (as it is distinguished from high-profit institutes) (Healey, 1992, p. 157). Mardookhi considers the optionality of cooperative activities as the most important characteristics. He states that the activities done by the individuals as their job or duty, for direct benefit in short-term, for direct or indirect force, tangible or intangible force, and personal convenience can be considered out of the scope of cooperation. From his viewpoint, political and social cooperation is determined by the individual's active relationship with consultative and public units, associations and local activities (Mardookhi, 1993, p. 72). MohseniTabrizi has emphasized on optionality of cooperation, while defining social cooperation. From his viewpoint, "social cooperation refers to those optional activities from which the members of a society participate in neighborhood, city and village affairs and participate directly or indirectly in forming the social life of cooperation" (Mohseni, 1989, p. 108). Optional associations are considered the most important forming and organizing scope of cooperative activities in society. From this perspective, social cooperation has a close relationship with civil society. Sa'dAlddin Ibrahim (1995) mentions that civil society "is the background of organized, optional group cooperation in public sphere between individuals and government" (as cited in Chalbi, 1995, p. 288). Molinas has stated that successful interference with the civil society in the process of development leads to individual's effective cooperation (Molinas, 1998, p. 13). From Chalbi's point of view, voluntary associations are a kind of suitable founding for social cooperation. From one side, cooperative institutes connect the people to the society and increase the individual's cooperation in social affairs through absorbing their cooperation. From the other hand, they help the expansion of active, voluntary cooperation in people by developing social nets and strengthening the social accretion (Chalbi, op.cit:290). With regard to presented issues about conceptual environment of social cooperation, any conscious, voluntary, bilateral, group and to some extent organized action among people and groups for the sake of goals, needs and public benefits are considered as social cooperation (Vahida \& Niazi, 2003, pp. 117-145).

\subsection{Cooperative Citizen Characteristics}

Democracy and cooperation are two fragile issues. Against these two social processes, there are strong powers which do not have a good relation with law (against democracy). In this situation, the responsibility of the government driven from national will is much more related to attracting public thoughts toward Constitution, creating necessary fields for group work, cooperation and effective social interaction. In order to expand cooperative approach to different social subjects, society needs citizens who enjoy the necessary characteristics in the first place. In order to cooperate, people must be trained and necessary skills, approaches and information must be created. Cooperation entails necessary awareness, effective skills and productive approaches. Knowledge and skill in defining the subject, analyzing it, goal recognition, effective human relationship, decision making, group living and group spritit are the subjects which must be dealt with in individual's training for cooperation (Forester, 1989, p. 19).Cooperative individuals are flexible. Inflexible individuals decide alone, so they are not able to provide necessary arrangements for cooperation within themselves. One of these skills is self-thought. Teaching cooperation is not the final step. Reaching these skills need time for practice and revision. Within a society, we must prepare these chances for children. We must have environment and situations which are as clear as possible, along with adequate knowledge and reinforce the productive skills and attitudes related to cooperation. Surely, these issues must be taught; opportunities must be provided for exercising necessary skills. In most countries, it is done in public education period. Enabled citizens must have at least some characteristics like work ability, cooperation with others, group work spirit, ability to confront problems and difficulties as an active member of the society, the ability to consider insights and attitudes differences a natural subject in confronting issues, critical and systematic thought, solving problems non-violently, improving living situation, participation in social, political, cultural activities paying attention to human rights, the ability to accept defined and confirmed regulations in social relationship which is actually "game regulations", respect to 
others and accepting democratic frames in group work activities (Cogan, 1997, p. 73). We need to believe in the need to other's experiences. We need to learn how to take use of other's experiences. Cooperation exercises must begin with learning from others. Cooperative approaches link us with other members of the society, and is very effective for activity's quality and effectiveness. In order to take advantage of this method, all of us need necessary skills for scientific discussion, reasonable thought, being criticized, active interaction, tolerating other's view, scientific attitude toward issues and accepting natural and reasonable consequences of our behavior. Necessary skills for group work intrigues the cooperation, removes the fear of interaction and stimulates active methods, strengthen the learned materials, increase the recognition power, and makes decisions more effective. In order to use the advantages of cooperative approaches, all of us need to expand necessary skills for living in a group and renovate our attitudes toward cooperative activities effectively.

\subsection{Research Goals}

\subsubsection{General Goal}

-recognizing the effective factors on social cooperation decrease with regard to managing social cooperation absorption in managing urban zones (zone 3 in Isfahan).

\subsubsection{Strategic Goals}

-recognizing the effectiveness of individual roles in family on social cooperation decrease in urban zones (Zone 3 in Isfahan)

-recognizing the effectiveness of training on social cooperation decrease in urban zones (Zone 3 in Isfahan) -recognizing the effectiveness of cooperation on social cooperation decrease in urban zones (Zone 3 in Isfahan) -recognizing the effectiveness of education level on social cooperation decrease in urban zones (Zone 3 in Isfahan)

-recognizing the effectiveness of individual's motive on social cooperation decrease in urban zones (Zone 3 in Isfahan)

-recognizing the effectiveness of trust on authorities and organizations on social cooperation decrease in urban zones (Zone 3 in Isfahan)

-recognizing the effectiveness of habitancy status (non-nativeness) on social cooperation decrease in urban zones (Zone 3 in Isfahan).

\subsection{Research Questions and Hypotheses}

\subsubsection{Research Main Question}

What are the factors which cause social cooperation decrease in urban zones management (Zone 3 in Isfahan)?

\subsubsection{Research Hypotheses}

The research hypotheses have been designed in order to respond to research main question. Therefore, subsidiary hypotheses which have been presented with regard to main question are:

-It seems that the individual's role in family is among the effective factors of social cooperation decrease in urban zones management.

-It seems that training is among the effective factors of social cooperation decrease in urban zones management.

-It seems that trust on authorities and organizations is among the effective factors of social cooperation decrease in urban zones management.

-It seems that habitancy status (non-nativeness) is among the effective factors of social cooperation decrease in urban zones management.

-It seems that the effectiveness of cooperation is among the effective factors of social cooperation decrease in urban zones management.

-It seems that motive is among the effective factors of social cooperation decrease in urban zones management.

-It seems that education level is among the effective factors of social cooperation decrease in urban zones management.

\section{Methodology}

The methodology of this research includes documental and survey methods. 


\subsection{Statistical Population}

The statistical population of this research includes all the inhabitants of zone 3 in Isfahan who are above 18 years old, whose number is 111896 .

\subsection{Sampling Method}

The sampling method, here, is random. The individuals inhabited in zone 3 in Isfahan are categorized into fine geographical levels and the present sample of this research was selected randomly among inhabitants with regard to proportion of the geographical zones.

\subsection{Sample Size}

Since the quantity of our statistical population is 111896 , the sample size was determined from the Cochran's formula mentioned below.One of the formulas is used for calculation of the sample size. In the formula $-t$ is Variable size in the normal distribution, - $p$ is the Percentage distribution of the trait in the society which is the ratio of the percentage of people who have the trait under study, -q is the percentage of people lacking that trait in the society, - $d$ is the difference between the actual ratio trait in the society and the amount of the researcher's estimation of the trait existence in the society and $-\mathrm{N}$ is the population size of the study. The significant characteristic of the formula is that sample size could be involved and a more logical sample could be accessed.

$$
\begin{array}{cl}
n=\frac{\frac{t^{2} p q}{d^{2}}}{1+\frac{1}{N}\left(\frac{t^{2} p q}{d^{2}}-1\right)}=384 & n=\frac{\frac{(1.96)^{2}(.5 * .5)}{(.05)^{2}}}{1+\frac{1}{111896}\left(\frac{(1.96)^{2}(.5 * .5)}{(.05)^{2}}-1\right)} \approx 385 \\
\mathrm{t}=1.96 \quad \mathrm{p}=.5 & \mathrm{q}=.5 \quad \mathrm{~d}=.05 \quad \mathrm{~N}=111896
\end{array}
$$

\subsection{Data Collection Tools}

In this research, in order to gather the required data, necessary for testing the research hypotheses primary sources (interview and questionnaire) and secondary sources (books and articles, present documents and evidence, and internet resources) were used. The priority in primary sources is given to questionnaire.Data collection tools in this research, is a questionnaire on investigating the effective factors on social cooperation in urban zones management. This questionnaire has been designed by the current researchers of the present research and has two parts. The first part has 18 questions which assesses the rate of individuals' cooperation. In managing urban affairs (Zone 3 in Isfahan) and the second part have 11 questions which measure the rate of social cooperation barriers. This questionnaire has been graded through Likert's Spectrum (This spectrum is composed of five equal parts and the researcher, with regard to the research subject, submits some indexs to the participants in order to identify the tendency concerning the subject. The spectrum ranges from totally agree up to totally disagree. The researcher can assign the numbers from 1 to 5 to each part of the spectrum's parts. For example, the tendency of totally agree can be assigned number 5 and the tendency of totally disagree could be assigned number 1 and then each score for each expression is calculated). The validity of this research was calculated 0.95 through Crunbach's Alpha which indicates to be suitable.

\subsection{Data Analysis Methods}

One of the common divisions of statistics is dividing it to two categories: parametric and non-parametric. In simple words, in order to measure the hypotheses whose variables are quantitative, parametric statistics is used; and for measuring the hypotheses whose variables are qualitative, non-parametric statistics is used. We try to recognize the effective factors on individual's social cooperation in urban zones management (Zone 3 in Isfahan). In fact, our test is a non-parametric one which is related to $\mathrm{K}$ in independent group; two dimensional $\mathrm{X}^{2}$ test and Friedman's test were used to investigate the hypotheses.

\section{Research Findings}

\subsection{Inferential Statistics}

In this section, the gathered data are analyzed and investigated in order to respond to the research hypotheses.

\subsubsection{Statistical Analysis of Research Gathered Data}

\subsubsection{Kolmogrov-Smirnov (K-S) Test for Research Data Normalization}

With regard to the fact that the achieved significance level for individual's role in family gathered data is lower than research alpha $(\alpha=.05)$; therefore, the data related to the first hypothesis do not follow the normal function. So a non-parametric test should be used for analyzing and investigating the data which related to this hypothesis. 
With regard to the fact that the achieved significance level for training gathered data is lower than research alpha $(\alpha=.05)$, thus it can be conclude that the data related to second hypothesis do not follow the normal function. So a non-parametric test should be used for analyzing and investigating the data which related to this hypothesis.

With regard to the fact that the achieved significance level for trust on the authorities and organizations gathered data is lower than research alpha $(\alpha=.05)$, thus it can be conclude that the data related to third hypothesis do not follow the normal function. So a non-parametric test should be used for analyzing and investigating the data which related to this hypothesis.

With regard to the fact that the achieved significance level for habitancy status gathered data is lower than research alpha $(\alpha=.05)$, thus it can be conclude that the data related to fourth hypothesis do not follow the normal function. So a non-parametric test should be used for analyzing and investigating the data which related to this hypothesis.

With regard to the fact that the achieved significance level for cooperation effectiveness gathered data is lower than research alpha $(\alpha=.05)$, thus it can be conclude that the data related to fifth hypothesis do not follow the normal function. So a non-parametric test should be used for analyzing and investigating the data which related to this hypothesis.

With regard to the fact that the achieved significance level for motive gathered data is lower than research alpha $(\alpha=.05)$, thus it can be conclude that the data related to sixth hypothesis do not follow the normal function. So a non-parametric test should be used for analyzing and investigating the data which related to this hypothesis.

With regard to the fact that the achieved significance level for education level gathered data is lower than research alpha $(\alpha=.05)$, thus it can be conclude that the data related to seventh hypothesis do not follow the normal function. So a non-parametric test should be used for analyzing and investigating the data which related to this hypothesis.

Therefore, the gathered data do not follow the normal society, then non-parametric test such as Wilcoxon's and Friedman's methods are the most appropriate tools for testing hypotheses.

\subsubsection{Test Related to Accepting or Refusing the Research Hypotheses}

First hypothesis: It seems that an individual role (Note 1) in family is one of the effective factors on social cooperation decrease in urban zones management.

Table 1. observed and expected number related to the first hypothesis (Source: Field Study by the authors)

\begin{tabular}{cccc}
\hline Indices Dimensions & Observed N & Expected N & Residual \\
\hline Very low & 64 & 77 & -13 \\
Low & 63 & 77 & -14 \\
Medium & 115 & 77 & 38 \\
High & 78 & 77 & 1 \\
Very high & 65 & 77 & -12 \\
Total & 385 & & \\
\hline
\end{tabular}

Table 2. $\mathrm{X}^{2}$ test related to the first hypothesis (Source: Field Study by the authors)

\begin{tabular}{cc}
\hline Statistical Index & \\
\hline $\mathrm{X}^{2}$ test & 25,377 \\
Freedom degree & 4 \\
Significance level & .002 \\
\hline
\end{tabular}

Tables' interpretation: The observed and expected number values and their differences have been shown in Table 1; the value of $\mathrm{x}^{2}$, freedom degree of hypothesis test and significance level of hypothesis have been shown in Table 2.

According to this fact that the achieved significance level is lower than alpha value of the research $(\alpha=.5)$ for individual's role in family gathered data, thus the null hypothesis is rejected and the first hypothesis is accepted with regard to effectiveness of individual's role in family as a barrier for people's cooperation.

Second hypothesis: It seems that training is one of the effective factors on social cooperation decrease in urban zones management. 
Table 3. Observed and expected number related to the second hypothesis (Source: Field Study by the authors)

\begin{tabular}{cccc}
\hline Indices Dimensions & Observed N & Expected N & Residual \\
\hline Very low & 26 & 77 & -51 \\
Low & 39 & 77 & -38 \\
Medium & 26 & 77 & -51 \\
High & 167 & 77 & 90 \\
Very high & 127 & 77 & 50 \\
Total & 385 & & \\
\hline
\end{tabular}

Table 4. $\mathrm{X}^{2}$ test related to the first hypothesis (Source: Field Study by the authors)

\begin{tabular}{cc}
\hline Statistical Index & \\
\hline $\mathrm{X}^{2}$ test & 223,974 \\
Freedom degree & 4 \\
Significance level & .009 \\
\hline
\end{tabular}

Tables' interpretation: The observed and expected number values and their differences have been shown in Table 3 ; the value of $x^{2}$, freedom degree of hypothesis test and significance level of hypothesis have been shown in Table 4.

According to this fact that the achieved significance level is lower than alpha value of the research $(\alpha=.5)$ for training gathered data, thus the null hypothesis is rejected and the first hypothesis is accepted with regard to effectiveness of training as a barrier for people's cooperation.

Third hypothesis: It seems that trust on authorities and organizations is one of the effective factors on social cooperation decrease in urban zones management.

Table 5. Observed and expected number related to the third hypothesis (Source: Field Study by the authors)

\begin{tabular}{cccc}
\hline Indices Dimensions & Observed N & Expected N & Residual \\
\hline Very low & 26 & 77 & -51 \\
Low & 63 & 77 & -14 \\
Medium & 12 & 77 & -65 \\
High & 117 & 77 & 40 \\
Very high & 167 & 77 & 90 \\
Total & 385 & & \\
\hline
\end{tabular}

Table 6. $\mathrm{X}^{2}$ test related to the third hypothesis (Source: Field Study by the authors)

\begin{tabular}{cc}
\hline Statistical Index & \\
\hline$X^{2}$ test & 217,169 \\
Freedom degree & 4 \\
Significance level & .034 \\
\hline
\end{tabular}

Tables' interpretation: The observed and expected number values and their differences have been shown in Table 5; the value of $x^{2}$, freedom degree of hypothesis test and significance level of hypothesis have been shown in Table 6.

According to this fact that the achieved significance level is lower than alpha value of the research $(\alpha=.5)$ for trust on authorities and organizations gathered data, thus the null hypothesis is rejected and the first hypothesis is accepted with regard to effectiveness of trust on authorities and organizations as a barrier for people's cooperation.

Fourth hypothesis: It seems that habitacy statue (non nativeness) is one of the effective factors on social cooperation decrease in urban zones management. 
Table 7. Observed and expected number related to the fourth hypothesis (Source: Field Study by the authors)

\begin{tabular}{cccc}
\hline Indices Dimensions & Observed N & Expected N & Residual \\
\hline Very low & 26 & 77 & -51 \\
Low & 37 & 77 & -40 \\
Medium & 39 & 77 & -38 \\
High & 142 & 77 & 65 \\
Very high & 141 & 77 & 64 \\
Total & 385 & & \\
\hline
\end{tabular}

Table $8 . \mathrm{X}^{2}$ test related to the fourth hypothesis (Source: Field Study by the authors)

\begin{tabular}{cc}
\hline Statistical Index & \\
\hline $\mathrm{X}^{2}$ test & 181,377 \\
Freedom degree & 4 \\
Significance level & .002 \\
\hline
\end{tabular}

Tables' interpretation: The observed and expected number values and their differences have been shown in Table 7; the value of $\mathrm{x}^{2}$, freedom degree of hypothesis test and significance level of hypothesis have been shown in Table 8 .

According to this fact that the achieved significance level is lower than alpha value of the research $(\alpha=.5)$ for habitacy statue (non nativeness) gathered data, thus the null hypothesis is rejected and the first hypothesis is accepted with regard to effectiveness of habitacy statue (non nativeness) as a barrier for people's cooperation.

Fifth hypothesis: It seems that cooperation effectiveness is one of the effective factors on social cooperation decrease in urban zones management.

Table 9. observed and expected number related to the fifth hypothesis (Source: Field Study by the authors)

\begin{tabular}{cccc}
\hline Indices Dimensions & Observed N & Expected N & Residual \\
\hline Low & 26 & 96.3 & -70.3 \\
Medium & 26 & 96.3 & -70.3 \\
High & 65 & 96.3 & -31.3 \\
Very high & 268 & 96.3 & 171.8 \\
Total & 385 & & \\
\hline
\end{tabular}

Table 10. $\mathrm{X}^{2}$ test related to the fifth hypothesis (Source: Field Study by the authors)

\begin{tabular}{cc}
\hline Statistical Index & \\
\hline $\mathrm{X}^{2}$ test & 419,166 \\
Freedom degree & 3 \\
Significance level & .038 \\
\hline
\end{tabular}

Tables' interpretation: The observed and expected number values and their differences have been shown in Table 9; the value of $x^{2}$, freedom degree of hypothesis test and significance level of hypothesis have been shown in Table 10.

According to this fact that the achieved significance level is lower than alpha value of the research $(\alpha=.5)$ for cooperation effectiveness gathered data, thus the null hypothesis is rejected and the first hypothesis is accepted regardingthe cooperation effectiveness as a barrier for people's cooperation.

Sixth hypothesis: It seems that motive is one of the effective factors on social cooperation decrease in urban zones management. 
Table 11. Observed and expected number related to the sixth hypothesis (Source: Field Study by the authors)

\begin{tabular}{cccc}
\hline Indices Dimensions & Observed N & Expected N & Residual \\
\hline Very low & 88 & 77 & 11 \\
Low & 63 & 77 & -14 \\
Medium & 91 & 77 & 14 \\
High & 52 & 77 & -25 \\
Very high & 91 & 77 & 14 \\
Total & 385 & & \\
\hline
\end{tabular}

Table 12. $\mathrm{X}^{2}$ test related to the sixth hypothesis (Source: Field Study by the authors)

\begin{tabular}{cc}
\hline Statistical Index & \\
\hline $\mathrm{X}^{2}$ test & 17,325 \\
Freedom degree & 4 \\
Significance level & .002 \\
\hline
\end{tabular}

Tables' interpretation: The observed and expected number values and their differences have been shown in Table 11; the value of $x^{2}$, freedom degree of hypothesis test and significance level of hypothesis have been shown in Table 12.

According to this fact that the achieved significance level is lower than alpha value of the research $(\alpha=.5)$ for motive gathered data, thus the null hypothesis is rejected and the first hypothesis is accepted with regard to effectiveness of motive as a barrier for people's cooperation.

Seventh hypothesis: It seems that education level is one of the effective factors on social cooperation decrease in urban zones management.

Table 13. Observed and expected number related to the seventh hypothesis (Source: Field Study by the authors)

\begin{tabular}{cccc}
\hline Indices Dimensions & Observed N & Expected N & Residual \\
\hline Very low & 39 & 77 & -38 \\
Low & 37 & 77 & -40 \\
Medium & 143 & 77 & 66 \\
High & 39 & 77 & -38 \\
Very high & 127 & 77 & 50 \\
Total & 385 & & \\
\hline
\end{tabular}

Table 14. $\mathrm{X}^{2}$ test related to the seventh hypothesis (Source: Field Study by the authors)

\begin{tabular}{cc}
\hline Statistical Index & \\
\hline $\mathrm{X}^{2}$ test & 147,325 \\
Freedom degree & 4 \\
Significance level & .007 \\
\hline
\end{tabular}

Tables' interpretation: The observed and expected number values and their differences have been shown in Table13; the value of $\mathrm{x}^{2}$, freedom degree of hypothesis test and significance level of hypothesis have been shown in Table 14.

According to this fact that the achieved significance level is lower than alpha value of the research $(\alpha=.5)$ for education level gathered data, thus the null hypothesis is rejected and the first hypothesis is accepted with regard to effectiveness of education level as a barrier for people's cooperation. 
Table 15. Friedman test (Source: Field Study by the authors)

\begin{tabular}{|c|c|c|c|c|}
\hline Question & \multicolumn{4}{|c|}{ Is there a significant difference between the calculated rates? } \\
\hline \multirow{2}{*}{$\begin{array}{c}\text { Research } \\
\text { hypotheses }\end{array}$} & Null hypothesis: & \multicolumn{3}{|c|}{ The difference between the calculated rates is significance. } \\
\hline & First hypothesis: & \multicolumn{3}{|c|}{ The difference between the calculated rates is not significance. } \\
\hline \multirow{2}{*}{$\begin{array}{l}\text { Statistical } \\
\text { hypotheses }\end{array}$} & Null hypothesis: & \multicolumn{3}{|c|}{$\mathrm{H}_{0}: \mu_{1}=\mu_{2}=\mu_{3}=\mu_{4}=\mu_{5}=\mu_{6}=\mu_{7}=\mu_{8}$} \\
\hline & First hypothesis: & \multicolumn{3}{|c|}{ At least, they are different about two times of the average } \\
\hline \multirow{11}{*}{ 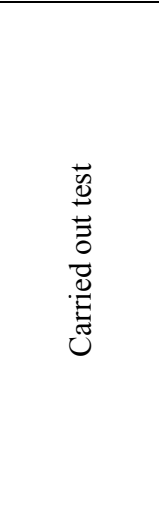 } & \multicolumn{4}{|c|}{ Friedman } \\
\hline & \multicolumn{2}{|c|}{ Ranks } & & \\
\hline & \multicolumn{2}{|r|}{ Mean Rank } & \multicolumn{2}{|c|}{ Test Statistics $^{\text {a }}$} \\
\hline & Hypothesis 1 & 2.95 & $\mathrm{~N}$ & 385 \\
\hline & Hypothesis 2 & 4.34 & Chi- square & 476.4366 \\
\hline & Hypothesis3 & 4.41 & $\mathrm{df}$ & 6 \\
\hline & Hypothesis4 & 4.30 & Asymp. Sig. & .000 \\
\hline & Hypothesis 5 & 5.44 & & \\
\hline & Hypothesis6 & 3.12 & & \\
\hline & Hypothesis 7 & 3.44 & & \\
\hline & \multicolumn{4}{|c|}{ a. Friedman test } \\
\hline Test result & \multicolumn{4}{|c|}{$\begin{array}{l}\text { In this test, with regard to this fact that the significance level is lower than } 0.05 \text { (above table), there is a } \\
\text { significance difference between the calculated rates. Therefore, the null hypothesis is confirmed. In the } \\
\text { following section, it will be explained fully. }\end{array}$} \\
\hline
\end{tabular}

Table 16. Friedman test result (Source: Field Study by the authors)

\begin{tabular}{|c|c|c|c|}
\hline \multirow{9}{*}{ 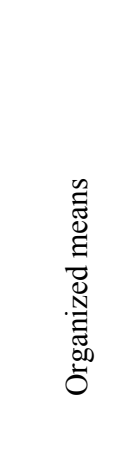 } & \multicolumn{3}{|c|}{$\begin{array}{l}\text { The comparison of given factors' rate with social barriers on individual's } \\
\text { managing urban zones }\end{array}$} \\
\hline & factor & Hypothesis & mean \\
\hline & Cooperation effectiveness & Hypothesis 5 & 5.44 \\
\hline & Trust on the authorities and organizations & Hypothesis 3 & 4.41 \\
\hline & training & Hypothesis 2 & 4.34 \\
\hline & Habitancy status(non-nativeness) & Hypothesis 4 & 4.30 \\
\hline & Education level & Hypothesis 7 & 3.44 \\
\hline & motive & Hypothesis 6 & 3.12 \\
\hline & Individual's role in family & Hypothesis 1 & 2.95 \\
\hline Test result & $\begin{array}{l}\text { With regard to the above mentioned table, it } \\
\text { questionnaire, the cooperation effectiveness le } \\
(0.05) \text { and the individual's role in family has lea }\end{array}$ & $\begin{array}{l}\text { from the view } \\
\text { lered as the me }\end{array}$ & $\begin{array}{l}\text { S filling out the } \\
\text { cial cooperation }\end{array}$ \\
\hline
\end{tabular}

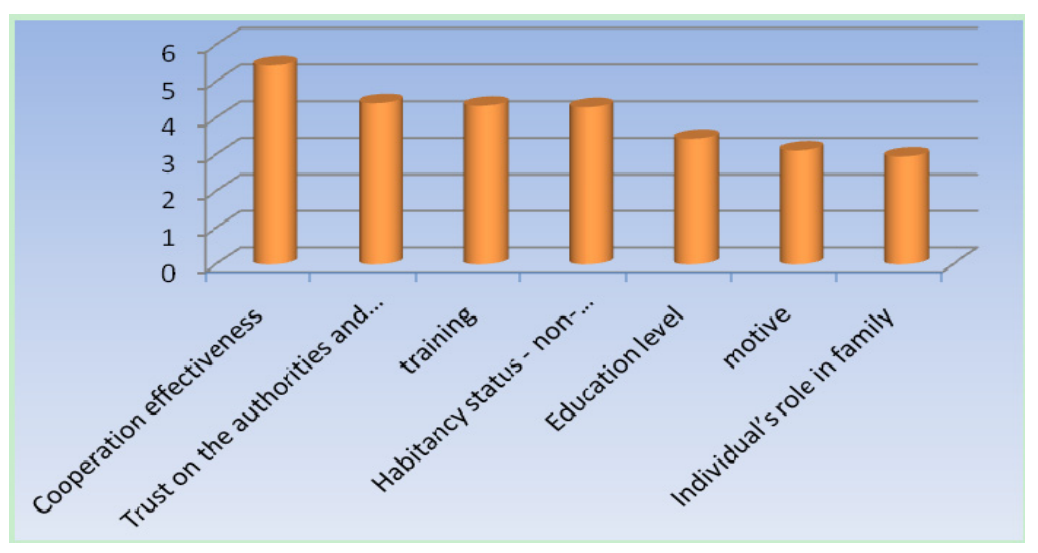




\section{Research Results}

Having analyzed the gathered data, it is tried to provide appropriate answers for research hypotheses with regards to acquired consequences of the research findings. Therefore, because our goal in this piece of research is to recognize he effective factors on social cooperation decrease with regards to attracting social cooperation management in urban zones management, questionnaires were designed and distributed between over 18 year-old individuals who inhabited in Zone 3 in Isfahan. Following are the barriers of individual's cooperation in urban zones management which were introduced as the hypotheses of our research.

\subsection{Individual's Role in Family}

$\mathrm{X}^{2}$ test has been used in order to reach the answer for the first hypothesis of research. In this test the achieved significance level is lower than 0.5 ; thus the individual's role in family is recognized as a barrier to social cooperation in urban zones management (urban zone 3 in Isfahan).

\subsection{Training}

$\mathrm{X}^{2}$ test has been used in order to reach the answer for the second hypothesis of research. In this test the achieved significance level is lower than 0.5 ; thus training is recognized as a barrier to social cooperation in urban zones management (urban zone 3 in Isfahan).

\subsection{Trust on the Authorities and Organizations}

$\mathrm{X}^{2}$ test has been used in order to reach the answer for the third hypothesis of research. In this test the achieved significance level is lower than 0.5 ; thus Trust on the authorities and organizations is recognized as a barrier to social cooperation in urban zones management (urban zone 3 in Isfahan).

\section{4 Habitancy Status.}

$\mathrm{X}^{2}$ test has been used in order to reach the answer for the fourth hypothesis of research. In this test the achieved significance level is lower than 0.5 ; thus Habitancy status (non-nativeness) is recognized as a barrier to social cooperation in urban zones management (urban zone 3 in Isfahan).

\subsection{Cooperation Effectiveness}

$\mathrm{X}^{2}$ test has been used in order to reach the answer for the fifth hypothesis of research. In this test the achieved significance level is lower than 0.5 ; thus Cooperation effectiveness is recognized as a barrier to social cooperation in urban zones management (urban zone 3 in Isfahan).

\subsection{Motive}

$\mathrm{X}^{2}$ test has been used in order to reach the answer for the sixth hypothesis of research. In this test the achieved significance level is lower than 0.5 ; thus motive is recognized as a barrier to social cooperation in urban zones management (urban zone 3 in Isfahan).

\subsection{Education Level}

$\mathrm{X}^{2}$ test has been used in order to reach the answer for the sixth hypothesis of research. In this test the achieved significance level is lower than 0.5 ; thus Education level is recognized as a barrier to social cooperation in urban zones management (urban zone 3 in Isfahan).

\section{Suggestions}

With regard to achieved consequences, social cooperation barriers in urban zones management (Zone 3 in Isfahan) grading and effectiveness are contrasted against each other. Paying attention to the following table, it is suggested that the priority presented here must be the base for long-term decisions if the authorities are seeking to remove the barriers in urban zones management (Zone 3 in Isfahan). 
Table 17. Priorities for social cooperation decreasing factors for decision making to remove them (Source: Field Study by the authors)

\begin{tabular}{cc}
\hline Priority & Respected barrier \\
\hline 1 & Cooperation effectiveness \\
2 & Trust on the authorities and organizations \\
3 & training \\
4 & Habitancy status(non-nativeness) \\
5 & Education level \\
6 & motive \\
7 & Individual's role in family \\
\hline
\end{tabular}

In order to reach a useful consultative process, in the first place, a three-step independent, repetitive consultation current control the process: 1). Focus on public meetings, 2). Being sure that the results of the first stage has been interpreted correctly and possible solutions for the future have been discussed, 3). Giving chance to public for testing the substitute future according to a pre-written document.

-social consultation should be utilized in order to form fundamental long term service plans which aims to be accepted by the plural viewpoint of the society and establishing vaster political fields for a society which tends to allocate more resources to local units, more commitment and social capital formation.

-forming Assembly management team or reference group for advisory tips.

-Establishing cooperative workshops in some points of the city in order to invite the citizens and civil stockholders to engage.

-Calling upon citizens through filling out questionnaires, net questionnaires or writing suggestions.

-forcing citizens to discuss the future of substitute city, inevitably includes some logistic challenges such as the absence of some groups of people in decision making, or their failure to response to consultative and commitment strategies - social and economical defects might affect assistance to the official consultative processes. Individuals and groups with different characters might influence the cooperation paying attention to differences, defects or barriers (for example, inability or handicappers, nativeness, elderly people, homelessness, immigrants and refugees). Furthermore, communication and consultation with many of the people can be difficult due to lack of time and motive to the questions of social cooperation workshops. Also, direct and instant suggestions for the people's living style and several other instances forces us to seek for structural, operational, developmental changes and staff training in our schedule.

\section{References}

Alghanami, M. R. (1990). Rural poverty Crisis: can participation eliminate it? Translated by Naser Oktae'e. Rustavatose'e (village and Development) quarterly. No. 5. Tehran: Markaz-e-Motaleatva Tahghighat Jahad Sazandegi Publication.

Almond. A., \& Pavel, B. J. (2000). Political Cooperation and participation of citizens. Translated by Ali Reza Tayyeb, Etela'ateghtesadi-seyasi (Economic-political information) No.163-164.

Amalric, F. (1998). Collaboration between local Administrations and local communities in the Age of Globalization: The Example of Switzerland. Report from a work shop by the society for international [SID] and the institute for Federalism [university of Fribourg], Murten, 24-26 April 1998.

Ames, S. (1997). Aguide to community visioning. Washington DC: American planning Association.

Ansari, M. E. (1995). Recognition and Prerequisites of Cooperational Management in Operational System. Modiriyatdolati (governmental management) Journal, 43-44.

Arani, M. (1999). Participation in education. Farhang Mosharekat (Participation Culture) Journal, 23.

Atal, U., \& Evin, L. S. (1999). Engaging poor people: several questions $\left(1^{\text {st }}\right.$ ed.). Translated by Iraj Pad. Poverty and Participation in Civil Society. Soroosh Publication. Tehran.

Azad Armaki, T. (1992). Effective Factors in More Success of People in Development. Development Culture, No.10, second year.Shaghayegh Publication. Tehran.

Azimi, R. (1993). Another view toward the role and significance of cooperation and assembly in improving educational management. Modiriatdar Amuzeshvaparvaresh (Management in Education) Quarterly. Daftare 
Behboode Modiriat Moavenat Barnameriziva Nirooye Ensani Vezarate Amoozeshva Parvaresh Publication. Fifth period. Tehran.

Azkiya, M., \& Gh. Ghafari. (2000). Analyzing Relationship Between Trust and Participation in Rural Areas of Kashan. Name-e-OloomeEjtemae'e (Social Science Letter), 17.

Biro, A. (1990). Social Science Culture. Translated by Bagher Sarookhani.

Blacher, Y. (2005). Changing the way Government works. public Administration today, OCT-Dec.

Brackertz, N., Zwart, I., Meredyth, D., \& Ralton, L. (2005). Community consultation and the Hard to Reach concepts and practices in victonan local vernment. main Report institute for social Research, swinburne university of Technology Victoria.

Cat, H., \& Murphy, M. (2003). What voice for the people? Categorising methods of public consultation. Australian journal of political scince, 38(93).

Chelbi, M. (1995). Discipline Sociology. Tehran: Ney Publication.

Cogan, J. J. (1997). Multidimensional citizenship: Eductaional policy for the 21st century, Final Report of the citizenship Education Policy study project, Funded by hesasakawa peace Foundation, Tokyo, Japan.

Forester, J. (1989). Planning in the face of power. Berkeley: University of California press.

Goulet, D. (1995). Development Ethics a Guid of theory and practice. London: Ned books.

Guy, D. (1991). Participational Development: Some Landscapes of Rural Mass Experiences.Translated by Esmat Maghami, Rusta and Tose'e (Village and Development) Book. Articles anthology. Markaze Tahghighatva Barrasi Masael Rustayivezarate Jahad Sazandegi Publication. Tehran.

Healey, P. (1998). Collaborative planning in a stakeholder society. Town planning Review, 69(1).

Healy, P. (1992). Planning through debate: the communicative Turn in planning theory. Town planning Review, 63.

Lane, M. (2005). Public participation in planning: an intellectual history. Australian Geographer, 36(3), 283-299. http://dx.doi.org/10.1080/00049180500325694

Mardookhi, B. (1993). People Participation in Development Process and a Plan for Measuring its Extent. Eghtesade Keshavarziva Tuse'e (Agriculture Economy and Development), 6. Tehran: Markaze Motaleat Barnameriziva Keshavarzi Publication.

Mohseni Tabrizi, A. (1989). Analyzing Participations Background of Rurals and Its relationship with Agriculture promotion. Tehran: Moavenate Tarvijva Mosharekate Mardomi Vezarate Jahad Sazandegi Publication.

Molinas, Jose R. (1998). The impact of inequality. Gender. External assisnanse ad social capital on local - level cooperation. World development, 26(3), 413-431. http://dx.doi.org/10.1016/S0305-750X(97)10066-3

Okley, P., \& Marsden, D. (1990). Participation Approach in Rural Development. Translated by Mansoor Mahmood Nejad. Tehran: Jahad Sazandegi Publication.

Patrick, J. B. (1994). Planning in Development Process. Translated by Gholam Reza Ahmadi \& Saeed Shahabi. Tehran: Ghoghnoos Publication.

Pieyre, J., \& Peters, G. (2000). Governance, politics and the state. London: Macmillan.

Rahnama, M. (1999). People's self development. London: zed books.

Tusi, M. (1990). Participation in Management and acquisition. Tehran: Markaz-e-Amuzesh-e- modiriyat Dolati Publication.

\section{Notes}

Note 1: It means the very role burdened by the family members. For example, in most Iranian families, Men work outside the home and the provision of family support is borne on them and women are responsible for housework and Upbringing and caring children as well as cooking. Sometimes, the children have to work outside the home like their fathers in order to help the family economically. In some cases women have to do so (in case of the widows, the divorced and the destitute). 